DOI: 10.17707/AgricultForest.62.2.22

\title{
Teerawong LAOSUWAN, Yannawut UTTARUK
ESTIMATING ABOVE GROUND CARBON CAPTURE USING REMOTE SENSING TECHNOLOGY IN SMALL SCALE AGROFORESTRY AREAS
}

\begin{abstract}
SUMMARY
The purpose of this study was to estimate the above ground carbon capture in small scale agroforestry areas of Inpang Community Forest Network, Sakon Nakhon Province, Thailand using remote sensing technology. This procedure was conducted from the satellite imagery Landsat 7 ETM+ information, which would be modified by atmospheric correction to verify it and generate Modified Soil Adjusted Vegetation Index 2 (MSAVI-2) along with model of determining Fractional Cover (FC) in order to determine the energy reflectance of vegetation index and fractional cover. The data obtained from the satellite through the above process were brought to determine the correlation with data from field surveys with statistical methods. The resultant equation was the $\mathrm{Y}=0.0259 \mathrm{e} 0.067 \mathrm{X}$. Such equation could be used to calculate the above ground carbon capture in the areas of interest. The results of estimating carbon content and carbon equivalent of small scale agroforestry areas with total space of 749.71 rai represented above ground carbon capture volume of 6,171.99 tons per rai or 22,630.63 tons of carbon dioxide equivalents (Ton $\mathrm{CO} 2$ Equivalent).
\end{abstract}

Keywords: Above ground carbon capture, remote sensing technology, small scale agroforestry.

\section{INTRODUCTION}

Carbon dioxide is the most primary greenhouse gas in the atmosphere. From the estimated increase of carbon dioxide finding, it is found that Carbon dioxide (CO2) has tendency to rise to about $440-660 \mathrm{ppm}$ by the year of 2050 . The change in the carbon cycle in forests is the most important factor affecting the changes in greenhouse gas concentrations of the atmosphere in the atmospheric release and absorption of carbon dioxide (Wasun et al., 2010). The major reasons that cause climate change is modification of patterns of land use. In particular, the destruction of forest resources by 20 percent results in the loss of carbon storage in xylems (Office of Environmental Policy and Planning, 2000). Forests have ability that can absorb and store $\mathrm{CO} 2$, accumulating carbon in biomass of different parts. The parts of trees include the stem, branches,

\footnotetext{
${ }^{1}$ Teerawong LAOSUWAN, (corresponding author: teerawong@msu.ac.th), Department of Physics, Faculty of Science, Khamrieng, Katarawichai, Mahasarakham, 44150, THAILAND, Yannawut UTTARUK,Department of Biology, Faculty of Science, Khamrieng, Katarawichai, Mahasarakham, 44150, THAILAND.

Notes: The authors declare that they have no conflicts of interest. Authorship Form signed online.
} 
leaves, and roots, which potentially accumulate $\mathrm{CO} 2$; it is depended on ecological system including wild species, the density of the forest, topography and environmental factors (Ogawa et al., 1965; Senpaseuth et al., 2009). To estimate the above ground carbon capture of forests is regarded as extremely important. It can be noted from the Kyoto protocol that has recognized the issues of Land Use, Land - Use Change and Forestry (LULUCF) as part of the reduction of greenhouse gas (IPCC, 2007; UNFCCC, 2010a; UNFCCC, 2010b; Chicago Climate Exchange, 2010; Laosuwan et al., 2011).

Remote sensing technology is considered as an important factor because the data from the satellite has evolved rapidly. In terms of record keeping and data analysis methods, The record system (Sensor) that has developed in terms of spatial resolution and spectral resolution causes a wide range of applications in various fields increases (Laosuwan, 2010; 2013). In addition, data from satellites today is well established that can be used in monitoring the dynamics of the natural and caused by human action in a timely manner. It can also be used in conjunction with Geographic Information System (GIS) effectively (Gomasathit et al., 2011; Laosuwan et al., 2011). Presently, remote sensing technology assists in the assessment of above the ground carbon capture. Satellite data can also be recorded because of the reflection of electromagnetic waves and simultaneous several wavelengths (Multi-spectral) that can take the properties of the wave, various electromagnetic. The satellite record estimates above-ground carbon capture in forest areas quickly (Lu et al., 2002; Schlerf et al., 2005; Patel et al.,2007; Samaniego et al.,2009; Kamusoko et al.,2009;Wang et al., 2011)]. This study aimed to estimate above ground carbon capture in small scale agroforestry areas of Inpang Community Network, Sakon Nakhon Province, Thailand using remote sensing technology.

\section{MATERIAL AND METHODS}

\section{The setting and data collection}

\section{Scope of Setting}

This study selected the small scale agroforestry areas of the farmers in Inpang Community Network, Sakon Nakhon Province, Thailand (Figure 1). As the pilot project in the province, the area was allocated in the boundary of $11 \mathrm{sub}$ districts. There were 50 family farmers joining the program. The total small scale agroforestry area was 749.71 rai $(1$ hectare $=6.25$ rai $)$ or $1,199,536 \mathrm{~m} 2$.

\section{Satellite Data}

This study used data from the Landsat-7 satellite in the Enhanced Thematic Mapper Plus (ETM +) 2013 by The US Geological Survey. Data can be downloaded from the website http://glovis.usgs.gov/. 


\section{Data Analysis}

The study was divided into two main steps below:

1) Analysis of satellite data from Landsat-7 ETM +.

2) Exploration and field data to determine the amount of carbon in the plot area.

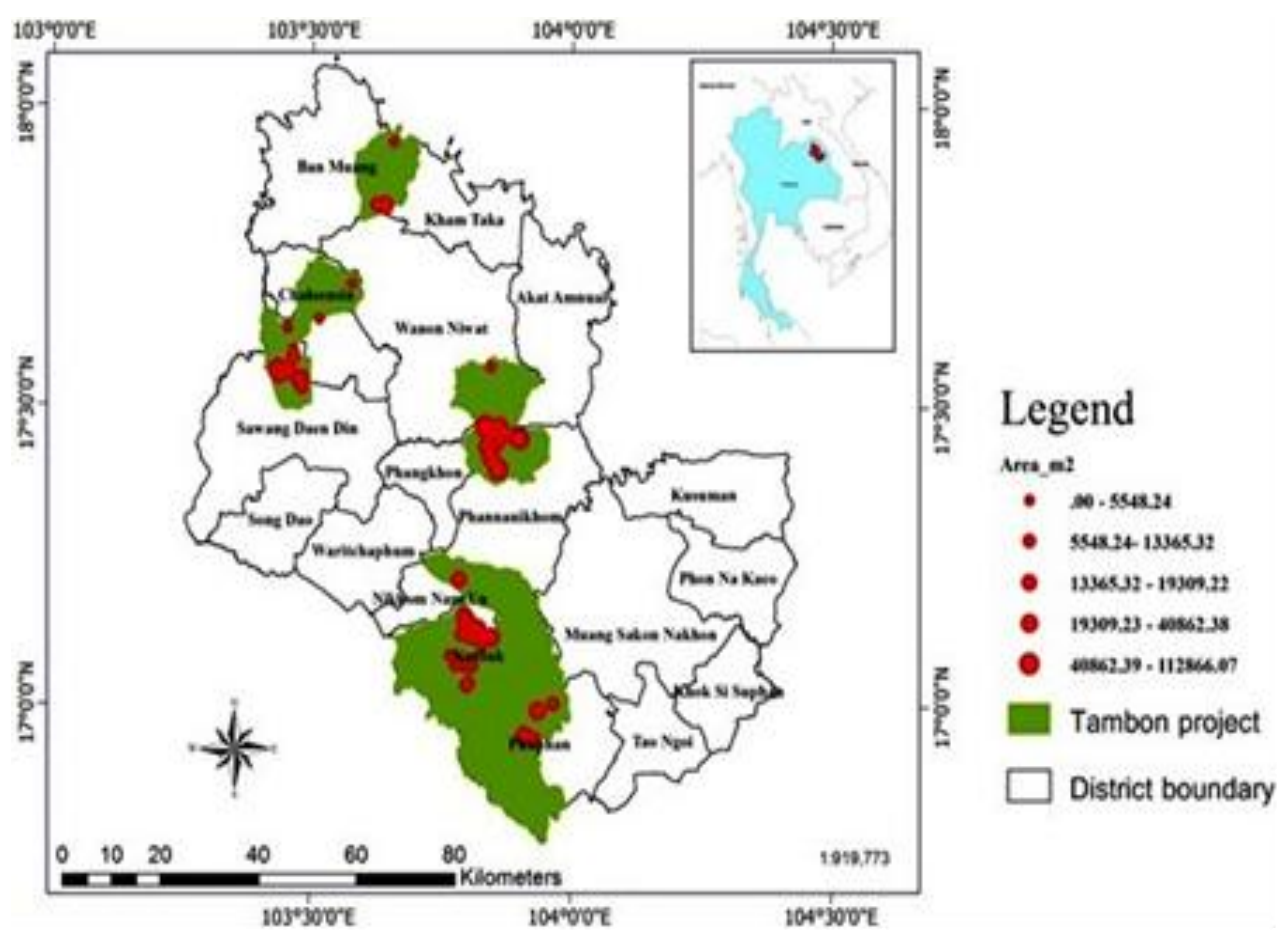

The final step will be to determine statistical correlation based on satellite Landsat-7 ETM + data and field survey data to calculate the carbon content per area.

Figure 1.Inpang Community Network, Sakon Nakhon Province, Thailand

\section{Analysis of Satellite Data from Landsat-7 ETM +}

(1) The satellite data from Landsat-7 ETM+ data downloaded from the USGS had errors caused by failed sensors on satellites. The crash of such information was called "Scan Line Corrector (SLC) failed". Thus, it is necessary to make adjustments to the data using the Gap-filling. In this study, the researcher recreated a tool to fix Gap-filling on the program ERDAS (Spatial Modeler Language: SML).

(2) Adjustments of Atmospheric Correction ensured the accurateness of the information conducted furnished by the act in two processes: 1) The process of making Convert Digital Number to Radiance Values and 2) the process of making Convert Radiance to TOA Reflectance. The study was modeled in two 
steps above mentioned on the program ERDAS (SML) by creating such models based on Equation 1 and Equation 2 below.

$$
L_{\lambda}=\text { Grescale } * \text { Qcal }+ \text { Brescale }
$$

Where;

$$
\text { Grescale }=\frac{\operatorname{LMAX}_{\lambda}-\operatorname{LMIN}_{\lambda}}{\text { Qcalmax }- \text { Qcalmin }}
$$

Brescale $=\operatorname{LMIN}_{\lambda}-\left[\operatorname{LMAX}_{\lambda}-\operatorname{LMIN}_{\lambda} /\right.$ Qcalmax - Qcalmin $] \times$ Qcalmin Where;

$L_{\lambda}=$ Spectral radiance at the sensor's aperture $\left[\mathrm{W} /\left(\mathrm{m}^{2} \mathrm{sr} \mu \mathrm{m}\right)\right]$

Qcal $=$ Quantized calibrated pixel value $[\mathrm{DN}]$

Qcalmin = Minimum quantized calibrated pixel value corresponding $\operatorname{LMIN}_{\lambda}$

Qcalmax $=$ Maximum quantized calibrated pixel value corresponding $\operatorname{LMAX}_{\lambda}$

$\operatorname{LMIN}_{\lambda}=$ Spectral at sensor radiance that is scaled to Qcalmin $\left[\mathrm{W} /\left(\mathrm{m}^{2} \mathrm{sr} \mu \mathrm{m}\right)\right]$

$L M A X_{\lambda}=$ Spectral at sensor radiance that is scaled to $\operatorname{Qcalmax}\left[\mathrm{W} /\left(\mathrm{m}^{2} \mathrm{sr} \mu \mathrm{m}\right)\right]$

Grescale $=$ Band specific rescaling gain factor $\left[\left(\mathrm{W} /\left(\mathrm{m}^{2} \mathrm{sr} \mu \mathrm{m}\right)\right) / \mathrm{DN}\right]$

Brescale $=$ Band specific rescaling bias factor $\left[\mathrm{W} /\left(\mathrm{m}^{2} \mathrm{sr} \mu \mathrm{m}\right)\right]$

$$
\rho_{\lambda}=\frac{\pi \times L_{\lambda} \times d^{2}}{E_{S U N_{\lambda}} \times \cos \theta_{s}}
$$

Where;

$\rho_{\lambda}=$ Unitless planetary reflectance

$\pi=3.14$

$L_{\lambda}=$ Spectral radiance at sensor's aperture $\left(\mathrm{Wm}^{-2} \mathrm{sr}^{-1} \mu \mathrm{m}^{-1}\right)$

$d=$ Earth-sun distance in astronomical units

$E_{S U N_{\lambda}}=$ Mean solar exoatmospheric irradiances

$\theta_{s}=$ Solar zenith angle

(3) The results of the data analysis in (2) were used for determining the energy reflectance of vegetation index with MSAVI-2, setting up the pixel of satellite data from Landsat-7 ETM +. If greater than 0 to 1 , it would be the vegetation. If the value was equal to or less than 0 and 0 , it was non-vegetation. Moreover, the finding of FC was to set up pixels to classify plants that were from 0 to 100. Also, such model was based on Equation 3 and Equation 4 below.

$$
M S A V I-2=\frac{(2 N I R+1)-\sqrt{(2 N I R+1)^{2}-8(N I R-\operatorname{Re} d)}}{2}
$$


Where;

$M S A V I-2$ = Vegetation index

$N I R=$ Near infrared band reflectance $(0.76-0.90 \mu \mathrm{m})$

$R E D=$ Red band reflectance $(0.60-0.70 \mu \mathrm{m})$

$$
F C=\frac{\left(V I-V I_{\text {open }}\right)}{\left(V I_{\text {canopy }}-V I_{\text {open }}\right)} \times 100
$$

Where;

$F C=$ Tree canopy fractional cover

$V I=$ Vegetation index

$V I_{\text {open }}=$ Vegetation index of open areas

$V I_{\text {canopy }}=$ Vegetation index of tree canop

Field Survey to Determine the Carbon Content in the Plot Areas

(1) Selection and creation of permanent plot

- Stratified method was used for areas selection, the knowledge from farmers who were members of the community, and then stratified random method was used to be a group study case. Then randomly select permanent plot according to the species or group of species cultivated plants or by age of transplant or agroforestry management system whose property is similar.

- The researchers made $20 \mathrm{~m}$ x $25 \mathrm{~m}$ of permanent sample plot in 50 plots in small scale agroforestry areas in order to assign 50 permanent plots as representatives of the study area of 749.71 rai. Later, the researcher collected data on types and amounts of large plants (wood with Diameter at Breast Height $(\mathrm{DBH})$ ranging from $4.5 \mathrm{~cm}$ or more) as well as measured the height of plants by using clinometers. Data obtained from the survey would be recorded in a record form.

(2) Estimation of Carbon Capture

The results of the data obtained from (1) were used to calculate the biomass of permanent plots using allometric equation for agroforestry plants in Thailand (Usa et al., 2011). Such method was used to estimate the above ground carbon capture as shown in the equation 5 .

$$
\begin{array}{ll}
W s=0.0389\left(D^{2} H\right)^{(0.9417)} & r^{2}=0.9106 \\
W b=0.0678\left(D^{2} H\right)^{(0.6618)} & r^{2}=0.8347 \\
W l=0.0084\left(D^{2} H\right)^{(0.7660)} & r^{2}=0.9109
\end{array}
$$


Where;

$W s=$ Stem; $W b=$ Branch; $W l=$ Leaf

\section{RESULTS AND DISCUSSION}

\section{Analysis of Satellite Landsat-7 ETM +}

(1) Results from the gap-filling to fix the failure of the scan line corrector (SLC) resulted in visual continuity of satellite data. The results of the gap-filling were shown in Figure 2.

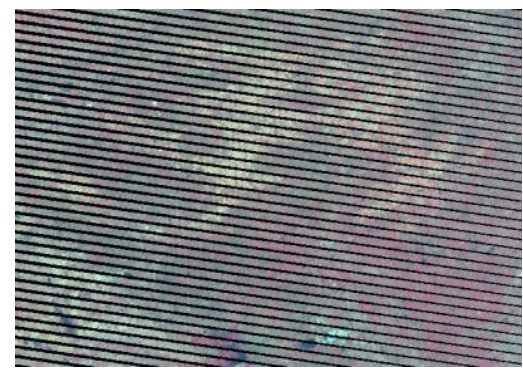

(a) Before Gab-filling

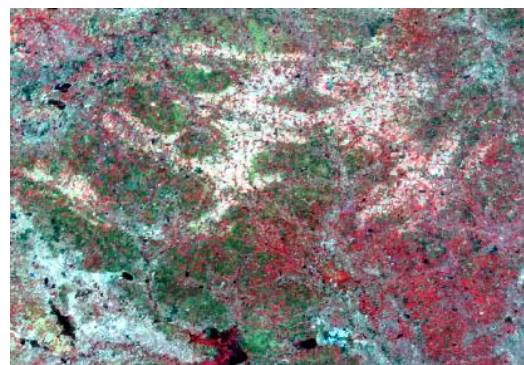

(b) After Gab-filling

Figure 2. Gap-filling method

(2) Developing a model of Atmospheric Correction to ensure the accuracy of the data was shown in Figure 3.

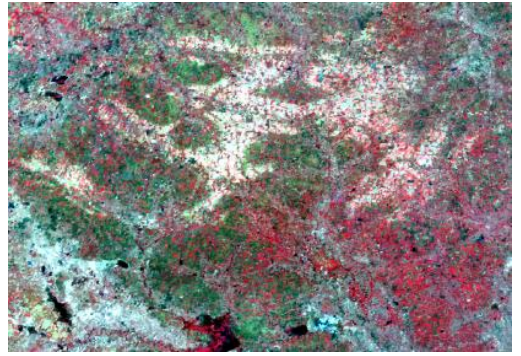

Before TOA

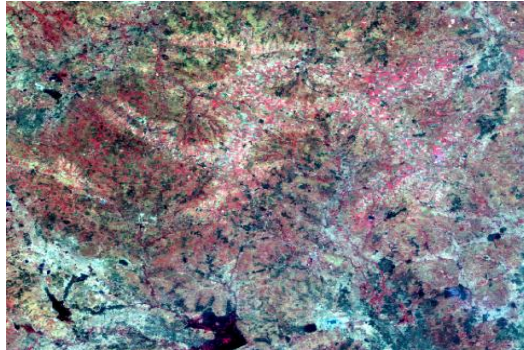

(b) After TOA

Figure 3. Atmospheric Correction (TOA)

(3) The results of determining the vegetation index with MSAVI-2 model and results of adjustment with the FC model were shown in Figure 4. 


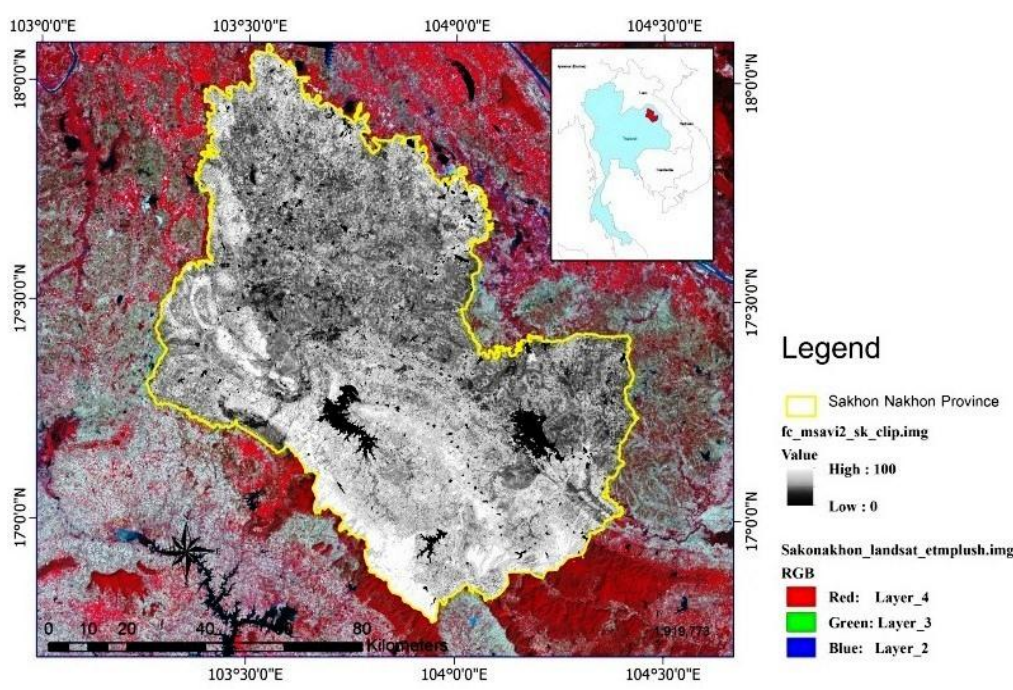

Figure 4. FC model

\section{Results of the field survey}

For 50 permanent plots in the study area, the researcher measured the height of trees with $4.5 \mathrm{~cm}$ or above and DBH of trees at a height of $130 \mathrm{~cm}$. Then the researcher recorded species of plants and heights of trees. Later, the above ground biomass was analyzed. However, the relationship between the FC and the carbon content could be shown in Figure 5. From the figure, it was found that when the number of FC was high, the carbon content increased as well. This has led equation $\mathrm{Y}=0.0259 \mathrm{e}^{0.067 \mathrm{X}}$ to represent the model. The result was shown in Figure 6, in which red color indicated the low volume of carbon capture and green color indicated the high volume of carbon capture respectively.

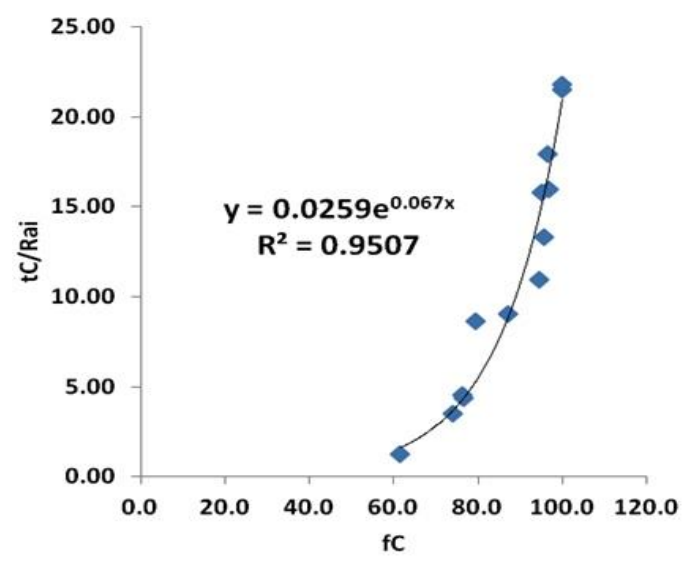

Figure 5. Relationship between the FC and the carbon content 


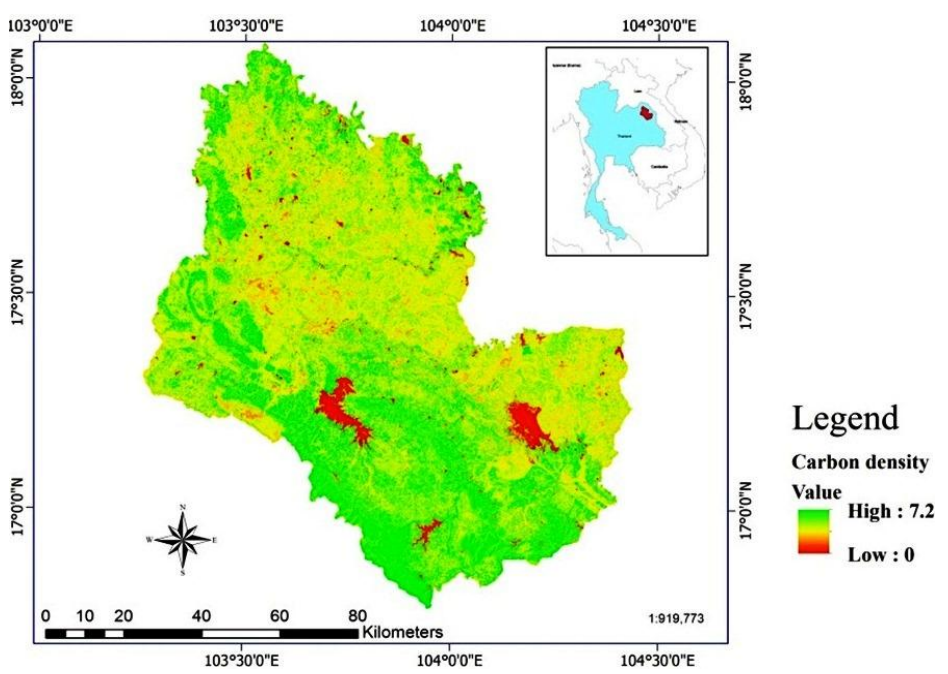

Figure 6. Carbon density

When the equation $\mathrm{Y}=0.0259 \mathrm{e}^{0.067 \mathrm{X}}$ was used to calculate the amount of above ground carbon capture per area (ton per rai) using the FC value from satellite Landsat 7 ETM +. The total size of small scale agroforestry areas of 749.71 rai found that the area with lowest density contained carbon capture at 1.00 ton per rai; the area with highest density contained carbon capture at 21.04 ton per rai. The mean was 8.87 ton per rais. The accumulation of carbon content was equivalent to $6,171.99$ ton per rai and calculated carbon content was equal to $22,630.63$ ton of carbon dioxide equivalents (Ton CO2 Equivalent). The plot with the lowest above ground carbon capture had 1.11 ton or 4.06 ton of carbon dioxide equivalents. The area with the highest above ground carbon capture had 547.76 ton per rai or 2,008.44 ton of carbon dioxide equivalents. The average above ground carbon capture was 123.44 ton or 452.61 ton of carbon dioxide equivalents.

In addition, the researcher has concluded results of the amount of carbon that could be analyzed with data from the satellite Landsat 7 ETM +, compared with data from field surveys, data from a total of 50 plots with Paired Sample ttest. The results showed a correlation of 0.926 , with statistically significance indifference of 0.01 . This indicated that the application of the data from the satellite Landsat 7 ETM + to estimate above ground carbon capture in the areas of Inpang Community Network, Sakon Nakhon Province, Thailand was very reliable.

\section{CONCLUSIONS}

The study on estimating above ground carbon capture in the area of small scale agroforestry of Inpang Community Network, Sakon Nakhon Province, Thailand by using the remote sensing technology can be concluded as follows. The total small scale agroforestry areas used was 749.71 rai, which enabled them 
to capture carbon content of $6,171.99$ ton per rai or $22,630.63$ ton of carbon dioxide equivalents. The small scale agroforestry areas are considered as the good reservoirs of carbon content because there are a few large-sized trees. This means that the small-sized to medium sized trees in the small scale agroforestry areas can grow further if local people in the areas help enrich them. The smallsized to medium sized trees in these areas have potential to accumulate the carbon content than large-sized trees because they have lower rate of growth. Additionally, some related organization and interested people can use the results of this study to be applied on the estimation of above ground carbon capture in the other areas of small scale agroforestry in Thailand.

\section{ACKNOWLEDGEMENTS}

This research was financially supported by Mahasarakham University.

\section{REFERENCES}

Chicago Climate Exchange (CCX). 2010. Forestry carbon sequestration offsets. Available at http://www.chicagoclimatex.com/content.jsf?id=242. Accessed 02 October 2011

Gomasathit, T., Laosuwan, T., Chunpang, P., Uraichun, Y. 2011. The Real Experience in GIS Teaching Aid by Using GIS Open-Source Software, International Journal of Geoinformatics, 7 (4): 63-67.

IPCC. 2007. Climate change 2007: IPCC fourth assessment report (AR4). In: Solomon S, Qin D, Manning M, Chen Z, Marquis M, Averyt KB, Tigora M, Miller HL (eds.) The physical science basis. Cambridge University Press, Cambridge, UK/New York, $996 \mathrm{p}$.

Kamusoko, C., Aniya, M., 2009. Hybrid classification of Landsat data and GIS for land use/cover change analysis of the Bindura district, Zimbabwe. Int. J. Remote Sens., $97-115$.

Office of Environmental Policy and Planning (OEPP). 2000. Thailand's national greenhouse gas inventory 1994. Bangkok.

Ministry of Science, Technology and Environment,

Ogawa, H., Yoda, K., Ogini, K. and Kira., T., 1965. Comparative Ecological Study on Three Main Type of Forest Vegetation in Thailand. Nature and Life in Southeast Asia. (4) : 49-80.

Laosuwan, T., Uttaruk, P.,Klinhom U., Butthep, C., Samek J. H., Skole, D, L. 2011. Development of Web-GIS Application for Carbon Sequestration in Thailand. International Journal of Geoinformatics, 7 (2), 41-47

Laosuwan, T., Chunpang, P., Sukkasena, S., 2011. Development of Robotic Aerial Remote Sensing System for Field Educational Purpose, International Journal of Geoinformatics, 7 (4): 21-27.

Laosuwan T, Pattanasethanon S, Sa-ngiamvibool W. 2013. Automated Cloud Detection of Satellite Imagery Using Spatial Modeler Language and ERDAS Macro Language. IETE Technical Review, 30: 183-90. 
Laosuwan, T., Uttarak, P., Klinhom, U., Butthep, C., Samek, J. H. and Skole, D. L. 2011. Development of Web-GIS Application for Carbon Sequestration in Thailand, International Journal of Geoinformatics, 7 (2): 41-47.

Lu, D., Mausel, P., Brondizio, E., Moran, E., 2002. Assessment of atmospheric correction methods for Landsat TM data applicable to Amazon basin LBA research. Int. J. Remote Sens, 23, 2651-2671.

Patel, N.K., Saxena, R.K., Shiwalkar, A., 2007. Study of fractional vegetation cover using high spectral resolution data. J. Indian Soc. Remote Sens.35, 73-79.

Samaniego, L., Schulz, K., 2009. Supervised classification of agricultural land cover using a modified k-NN technique (MNN) and Landsat remote sensing imagery. Remote Sens. 1, 875-895.

Schlerf, M., Alzberger, C., Hill, J., 2005. Remote sensing of forest biophysical variables using HyMap imaging spectrometer data. Remote Sens. Environ. 95, 177-194.

Senpaseuth P., Navanugraha C., and Pattanakiat S., 2009. The Estimation of Carbon Storage in Dry Evergreen and Dry Dipterocarp Forests in Sang Khom District, Nong Khai Province, Thailand Environment and Natural Resources Journal. 7(2). $1-11$.

Teerawong Laosuwan \& Pornchai Uttaruk. 2014. Estimating Tree Biomass via Remote Sensing, MSAVI 2, and Fractional Cover Model. IETE Technical Review, 31(5): 362-368.

Usa Klinhom,Teerawong Laosuwan , Pornchai Uttaruk, Rittirong Junggoth, Penkhae Thamsenanupap, Komgrit Wongpakam. 2011. Carbon Offset in forest Sector. Final Report Carbon Offset in forest Sector Project. National Research Council of Thailand (NRCT). 220p.

UNFCCC. (2010a). Clean development mechanism: methodologies: afforestation / Reforestationmethodologies. Approved A/R Methodologies. Available at http://cdm.unfccc.int/methodologies/ ARmethodologies/ approved_ar.html. Accessed 02 October 2011

UNFCCC. (2010b). Clean development mechanism: methodologies: small scale Afforestation / reforestation CDM methodologies. Methodologies for small scale A/R CDM project activities. Available at http://cdm.unfccc.int/methodologies/ SSCAR/ approved.html. Accessed 02 October 2011

Wang, G., Zhang, M., Gertner, G.Z., Oyana, T., McRoberts, R.E., Ge, H., 2011. Uncertainties of mapping aboveground forest carbon due to plot locations using national forest inventory plot and remotely sensed data. Scand. J. For. Res. 26, 360-373.

Wasun Jundang, Ladawan Puangchit and Sapit Diloksumpun. 2010. Carbon Storage of Dry Dipterocarp Forest and Eucalypt Plantation at Mancha Khiri Plantation, Khon Kaen Province. Thai Journal of Forestry. 29 (3) : 36-44. 